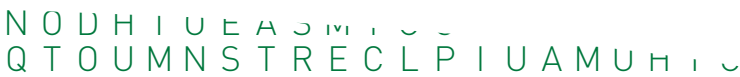

GWTUOI DREQR I UZENLORBEFBAr.

QNKDSAYPJDGLETUODDBEUBAFVNKr,

$P N \mathbf{O} \mathbf{R} \mathbf{Q}$ U E M C O N V E R T E R J H L M O KN I JUUH

$G T K Q O M G N N \vee U S G R V L A D G L E T U O A D G J J L Y C B$ w.

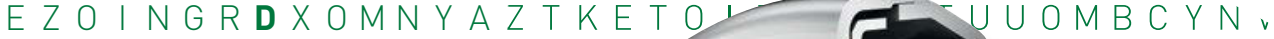

$D S N V C S E U L J N E W C L V O R Y$
$O S C Q Y J A L B R E L N F X T N$

I YNJORUZDFNGKLDO

$E Z J U A R N M I O G D N O I E$ $G L A K P E L-P M S E B \cup N Q$ $W N P Z B P E$ T B Q O P B D E
$O M B T N E H$ Y N Z W E D C V FENCROE PRWP O U U I KRBEFSEXCEFHOK O S E S OBPROS G B Z N $F E O F E|W A E Q R| \cup Z$ Z G E CWDA BWTR D X E $O Q W P J M F \mathbf{S} J H L M O K N$ C C P J C G T O D G L E TUC JPCGTVDRLETUOA D $\vee C J T Z G E$ B O I Z RW Q E A J S J T D S E K J H G F S L S J T D S Y R J HGF D S A EK J R C K O I J GRDCK I C $M O T Y Q O G N T Z D S Q O M G$ $T N U E|N R L U J G D| N G R E$ DCOOVCESOPMNVCSEY $J Y|Z Q|$ T C I NCWQYJAOB N J KVN N N D KDOBN J ORO I L A A O O U N R ONG I UARNHGOL UDMTBOBHMGRE B P B D L R B L A A O E U V NDONGIUARNHIOGDN $M O T M V$ A L U E Z E N H A N C E D V U S G K UDMTB TBHMGR I BDPBDLRBEFBAF LWSPLOCYQDMFEF $F E|D R I Q R I U Z T R E W Q L K J H G F D S A M M D r u X Y M L M O K N| J B H U Z G F$ CIMNSORECLPQACEZRWDXAYHBMWRZIRFVEGBZHNUJMIKOQA $P J M N|\mathbf{N} H L M O K N| J U H B Z G V T F C R D X E S N W A S R E C V F H K N U T E Q T F$ C GTJDGLETUOADG JLYCBMWRZIPSFHKTVNZLMOIJEUHBZGWR JTZUETOIZRWQETUOMBCYNVXADGJLKHESYSCBFGMHTILQNV 


\title{
ITC - Innovative Solutions for Torque Converters Pave the Way into the Future
}

\author{
Patrick Lindemann \\ Markus Steinberger \\ Thorsten Krause
}

D v

$\mathrm{J} Z \mathrm{MH}_{L}$

$A G Q S W \mid\llcorner\cdots$

F I MBCHSEHヒレ

C E C B S T P O I O D C V ᄃ レ.
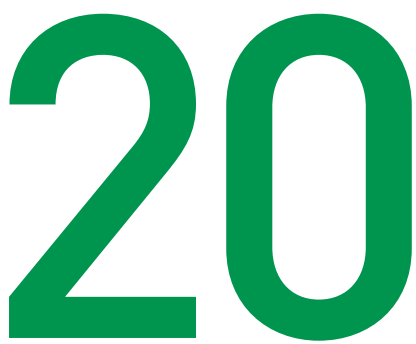

$D G \vee T Q U J X R E L K J H G F D S A \mid N_{1} \cdots$

YLMRTX A G YWPHCEQA YWS XE E C K,

$C X \vee N H O U B I J B Z G V T F C R D X E S N W A S K L$

$Z V T F L U J A D G Y C B M W R Z$ I P S F H K T VNZLMU.

$X D B P O R U T E T M B C Y N V X A D G J L K H E S Y S C B M B \iota$

DC SKUPOWRWZTWHNEDKUNWPONCA L V I K Z TWH IN

EHKLPFLKJKO I UZTREWQYXCVBNMIQWUOIUZTR

WDXAYHASGSVNPIZRWQSCGZNJ|MNSTRVNPIZRWQ_

$L Z \cup K O G \mid K C K P M N E S W L N C X W Z Y K F E D I O P P M N E S W L N C X$

$R \cup C Z G Z M Q G O D N \vee \cup S G R \vee L G R \vee K G E C E Z E M D N V \cup S G R \vee L G h$ QATSLOKZ I NEXOMNYAZTEWNFX JLRNIFEXOMNYAZTEW

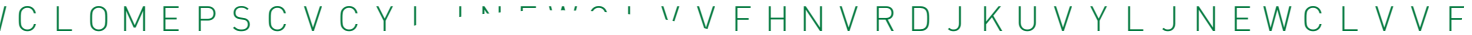
F A MUAN J Y $\cap \cdots$

KMN S R D O

L I E P N N

B S A T B

$P \mid E P$ I

$R \cup C Z$

B S A

D G V

$Y\llcorner\wedge$

C X

Z V

$X \mathrm{D}$ $S Q F H B Q F G O B R E L N F X T J C$ I ZPMFDRO I D F N KLDF `AUKZQH IOGDNOIERNL R EWS P D L R B F B A F V N K LKZQH IOGDNOIERNGN Z E M D V U S G R V L GR R K NSPDLRBEFBAFVNKF $M O L K J H G F D S A M M B V$ $B Z P H C E Q A Y W S X E E C$ $\checkmark V B Z G V T F C R D X E S N$ 10 Y C B MWR Z I P SFHK $B M B C Y N \vee X A D G J L K$ K Z TWHNEDKUNWPr

P OWRWZ TWHNEDKUNWPONCA

$F L K J K O \mid U Z T R E W Q Y X C \vee B N M$ HASESVNP|ZRWQSCGZN J|M GIKCKPMNESWLNCXWZYKFF I A S U S VNP | ZRWQ S C G Z N J I I KCKPMNESWLNCXWZYKF 'OXODNVUSGRVLGRVKG

1 I NEXOMNYAZTEWNF. ' $C Y L J N E W C L V \vee F H$. $\cap N \vee U S G R V L G F$ 


\section{Preface}

The torque converter has been a stable choice as a launch device for automatic transmissions for several decades. Global vehicle production in 2013 is estimated to be 83 million, with $43 \%$ of the vehicles are being equipped with a torque converter [1]. In particular, the North American and the Asian market show a high ratio of torque converters in new vehicles [2]. Additionally, the European market is experiencing a trend away from manual transmissions as some vehicles - especially in the luxury and higher torque segment - are offered only with planetary automatic transmissions and a torque converter.

The choice of transmission type is largely driven by its impact on the powertrain efficiency and comfort. With stricter regulation on $\mathrm{CO}_{2}$ emissions and the prospect of further tightening of emission regulation, the automotive industry has made designing for fuel efficiency a core goal, resulting in drag reduction, more defined combustion processes and increased electrification. Despite electrification, internal combustion engines are a core element of powertrain strategies and their optimization will drive improvements in the drivetrain.

Supercharging of downsized engines is a primary path to achieving the required efficiency improvements [8]. This technology has been used in motorsport applications for some time. However, the more widespread application of turbochargers in gasoline engines required additional developments such as direct injection, availability of durable turbochargers from TDI engines, and increased development pressure through the reduction of $\mathrm{CO}_{2}$ targets.

The increased specific power and torque compared to a naturally aspirated

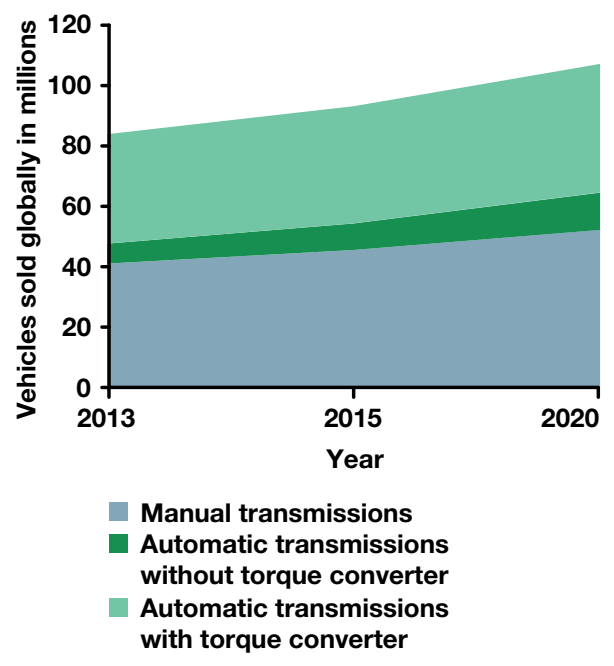

Figure 1 Global vehicle production [1]

engine allows the most often used driving conditions to be shifted to lower engine speeds. The reduced rotational speed minimizes losses caused by friction and improves the combustion efficiency.

With the improvements in engine technology, the driver does not have to accept a loss in performance for an increase in fuel efficiency. On the powertrain side however, the engine improvements change the boundary conditions for durability and comfort. The reduced number of cylinders, together with downspeeding and increased torque per cylinder leads to higher torsional vibrations. As a result, measures have to be taken to increase the durability of the drivetrain. The impact on comfort in the form of seat vibration, boom and rattle noise can be even greater and has to be met with highly capable damper technology. Finally, the use of a turbocharger can introduce a degradation of launch performance as a result of the turbo lag. In particular, small gasoline engines with 3 or 4 cylinders do not reach the peak torque until mid-operating speed.

In this environment, the drivetrain requires an element that is able to reduce 
torsional vibrations, provide the desired launch performance and achieve this with a minimum of added inertia and axial space. For automatic transmissions, the torque converter is the launch device of choice (Figure 1). Despite development in areas such as double clutch or automated manual transmissions, the majority of automatic and continuously variable transmissions are equipped with torque converters. This success of the torque converter raises the question of its origin and development potential for the future.

\section{History of the torque converter}

Torque converters were not the initial choice for a launch device. Early transmissions used friction clutches that were shifted manually or by means of centrifugal acceleration. With the advent of automatic transmissions and more refined passenger vehicles, the comfort and controllability aspect received more weight.
This lead to the first mass production use of a fluid coupling in 1940 by GM.

\section{Torque converters and fluid couplings in ships}

The history of torque converters and fluid couplings did not start in the automotive industry where they would later reach a production volume of millions of pieces per year. Instead, it started in the maritime industry. Hermann Föttinger designed a converter and a fluid coupling in 1905 (Figure 2) - which both have their specific advantages and disadvantages. The fluid coupling has a higher efficiency when the turbine speed is close to the impeller speed and the converter is able to provide a torque ratio to increase the output torque, which can be considered as an additional gear. After the initial patent, Föttinger also created several variations of his design that allowed him to change the torque transmission characteristic manually [4].

At this point, neither the converter nor the fluid coupling were envisaged as a launch device but changed the ship's propeller torque or decoupled the propeller
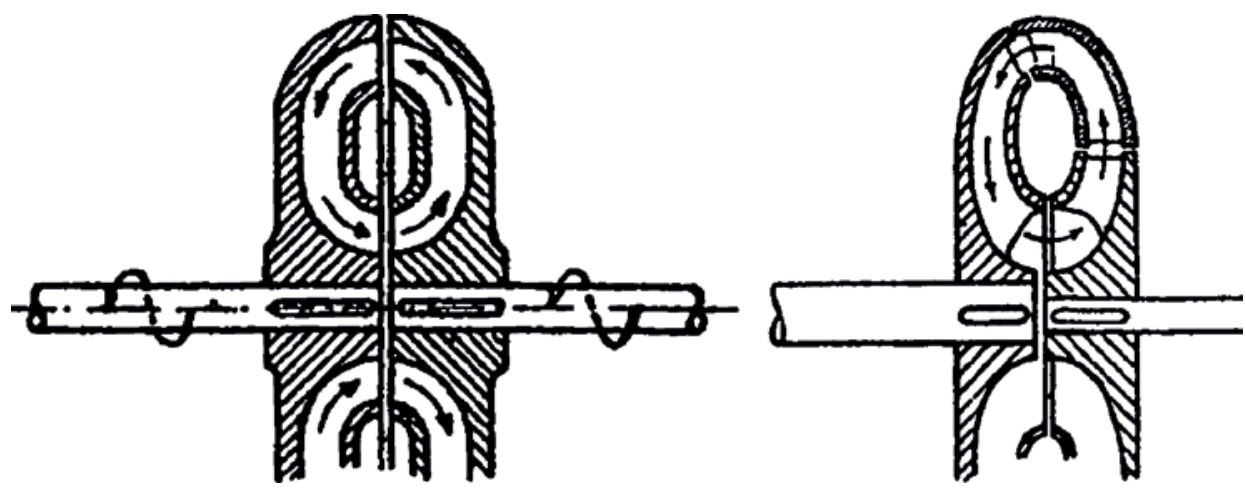

Figure 2 Hermann Föttinger's design for a fluid coupling (left) and a converter (right) [5], [6] 
from the drive shaft to prevent the propagation of a torque spike.

The first mention of a fluid coupling for passenger vehicles was made by Hermann Rieseler in 1925 [3]. The device consisted of a multitude of turbines and impellers. It remained an idea and did not reach the production phase because of its complexity.

\section{Improved torque converter controls}

A simplification of the torque converter design was achieved in 1928 when $\mathrm{H}$. Kluge, K. von Sanden and W. Spannhake (TRILOK Group) combined Föttinger's designs into a subassembly. It was the first time that the converter's stator was mounted on a one way clutch. This allowed the resulting design to provide the torque ratio of a converter and the high speed ratio efficiency of a fluid coupling. There was no need for additional controls to switch from

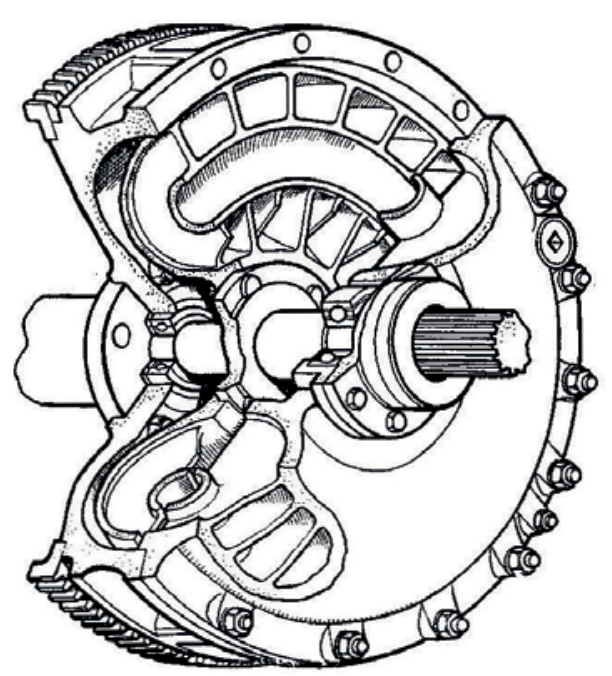

Figure 3 Daimler Company's fluid flywheel from 1928 [9] torque converter to coupling. The fluid's angle of attack relative to the stator blades provides the signal for the stator to spin freely and turn the hydrodynamic circuit into a coupling.

Even after the breakthrough of the TRILOK design, torque converters were not widely used in passenger vehicles. The first attempt to use a hydrodynamic clutch in a car was made in 1933 by the British Daimler Company Limited, which used a fluid flywheel in conjunction with a synchronized gearbox to avoid shift shocks.

\section{Mass production torque converter}

Although the use of a torque converter in automobiles was suggested in 1928, mass production did not start until 1940 . The designs combined a torque converter with the planetary automatic transmission and the fluid coupling was seen as an integral part of the transmission. The first mass production torque converter was introduced in the Oldsmobile HydraMatic as a safety, comfort and performance device. Since there was no shift lever and no clutch pedal, the driver had less interfaces with the car and could pay more attention to steering and braking. Comfort and performance are addressed by superior launch performance, reduced vibrations and improved shift quality.

Oldsmobile sold 10 million HydraMatic units [1], establishing planetary automatic transmissions with a fluid coupling in the automotive industry.

Following the stepwise introduction of features to the torque converter, the Packard Ultramatic introduced a lockup clutch in 1949. The so-called 'Direct Drive' hard locked the torque converter at high speeds and gave this transmission the fuel efficiency of a manual transmission. 


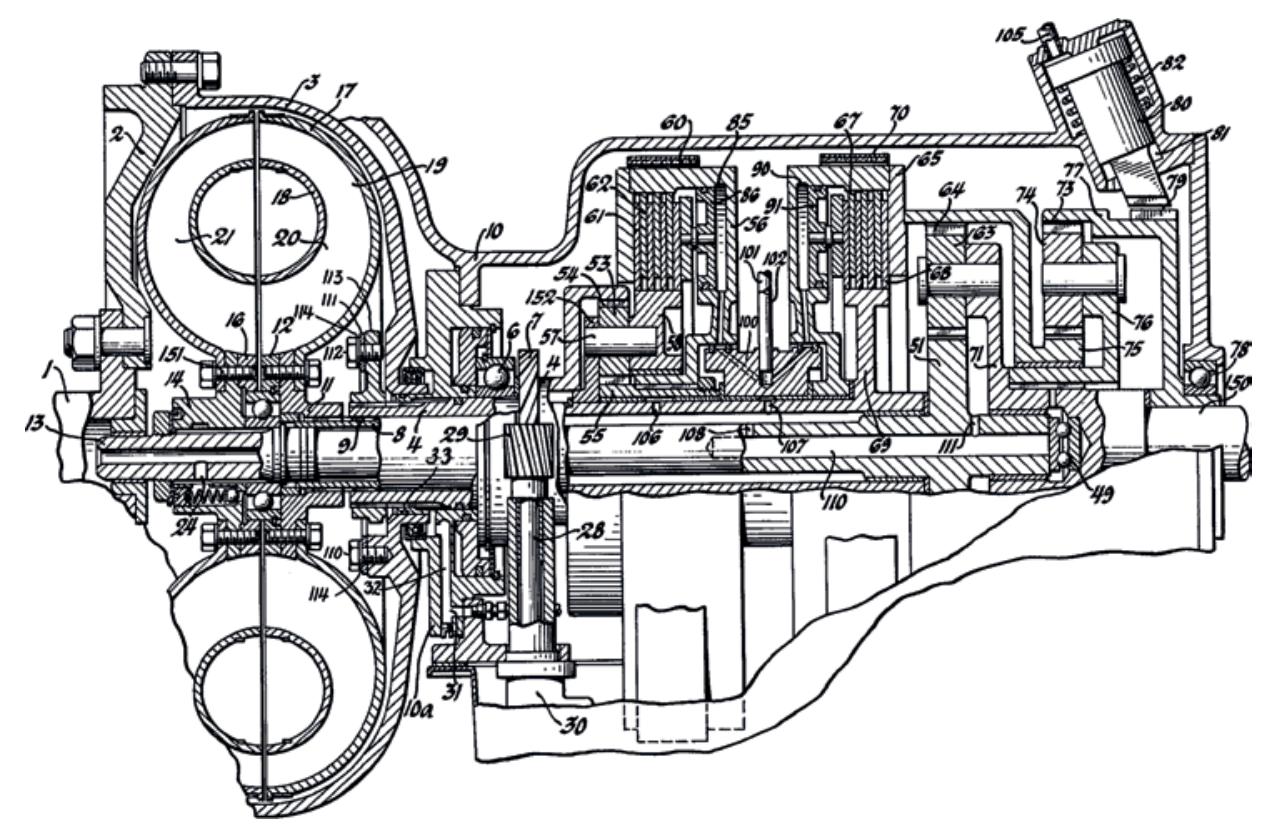

Figure 4 Oldsmobile Hydra-Matic with first large-scale production fluid coupling [2]

The introduction of the lockup clutch did not lead to immediate widespread adoption. Until the emphasis of efficiency that followed the oil crises in the 70's, the losses in an unlocked torque converter did not warrant the additional components and controls of a lockup clutch.

\section{Torque converter dampers}

A torque converter advantage that has not been mentioned so far is that the hydrodynamic circuit does not transmit the engine vibrations to the transmission. This allows the engine to run at speeds which would otherwise lead to excessive drivetrain vibrations. The undoubtedly beneficial introduction of a lockup clutch exposes the transmission to the previously avoided torsional vibrations. Therefore, the widespread adoption of lockup clutches in the 1980s also required devices to control vibrations in the drivetrain. This led to the advent of torque converter dampers.

The first torque converter damper was built by LuK in 1983 for use in the Ford AOD torque converter. With the damper, the engine torsional vibrations were attenuated to increase the driving conditions in which the lockup clutch can be fully locked. Initially, the lockup clutch was only engaged during cruising but with increasing demand for fuel efficiency, the duty cycle of the lockup clutch increased. This required increasingly complex dampers. The turbine damper that was introduced by LuK in 1994 did not only use springs to prevent the propagation of torsional vibrations along the drivetrain. This damper locked the turbine mass that used to be on the input shaft after the damper to the engine side side, thus eliminating a vibration mode. 


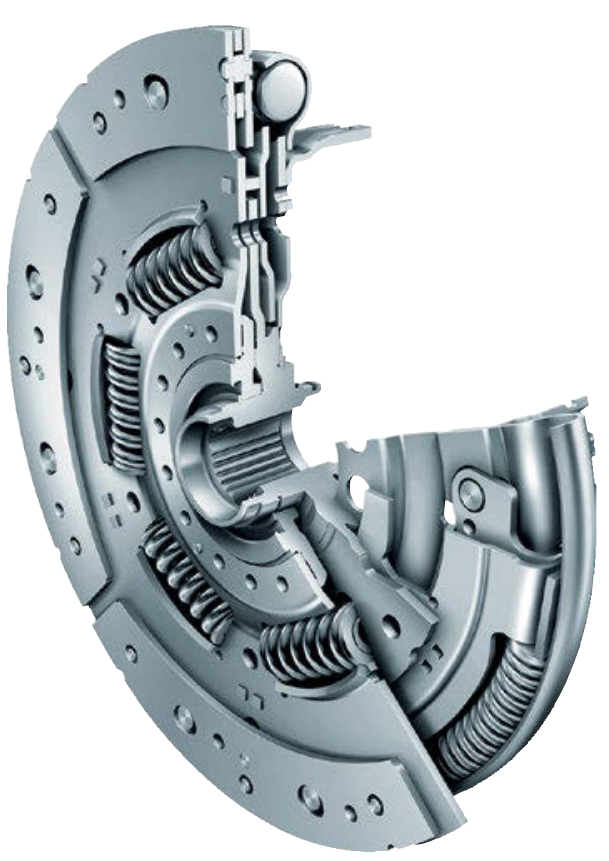

Figure 5 LuK torque converter damper with centrifugal pendulum absorber

Reaching a limit for spring volume and available inertia, torque converter dampers had to be based on a different principle to reduce the torsional vibrations of modern engines. As described above, improvements in engine efficiency directly lead to the demand for improved dampers.

Serving this demand, LuK introduced a torque converter damper in 2010 that used the centrifugal pendulum absorber principle. This allowed the lockup clutch to be engaged at engine speeds down to $1,000 \mathrm{rpm}$, covering the majority of typical driving, further improving the powertrain's efficiency.

\section{Drivers for torque converter development}

Following their long history, torque converters are an indispensable component of modern automatic transmissions. Their evolution leads to permanent adaptations and the current generation can be best understood with the guiding principle of value enhanced design. Current LuK torque converters are developed with the focus on the areas of performance increase, space reduction, cost reduction and higher efficiency.

Using the value enhanced design philosophy, components and subassemblies are strictly designed to meet the performance, space and cost targets. Supporting this goal, a modular design approach is used. This allows the torque converter to be customized to meet different objectives with a maximum focus on cost.

Performance improvements target the drivetrain efficiency and are achieved through reduction of the torque converter's weight and inertia, improved damper performance and improved efficiency of the hydrodynamic circuit.

Measures can be introduced gradually, such as stress optimization to reduce sheet metal thickness or directional design changes such as component replacements. A comparison between a torque converter design from 2005 and its successor from 2013 shows that the weight was reduced by $2.1 \mathrm{~kg}$ while the maximum torque converter efficiency remained stable at $90 \%$ and the damper windup increased by $31 \%$.

The axial length of the torque converter more so than its radial size is a key element of the power train's size. Crash test and aerodynamic requirements limit 

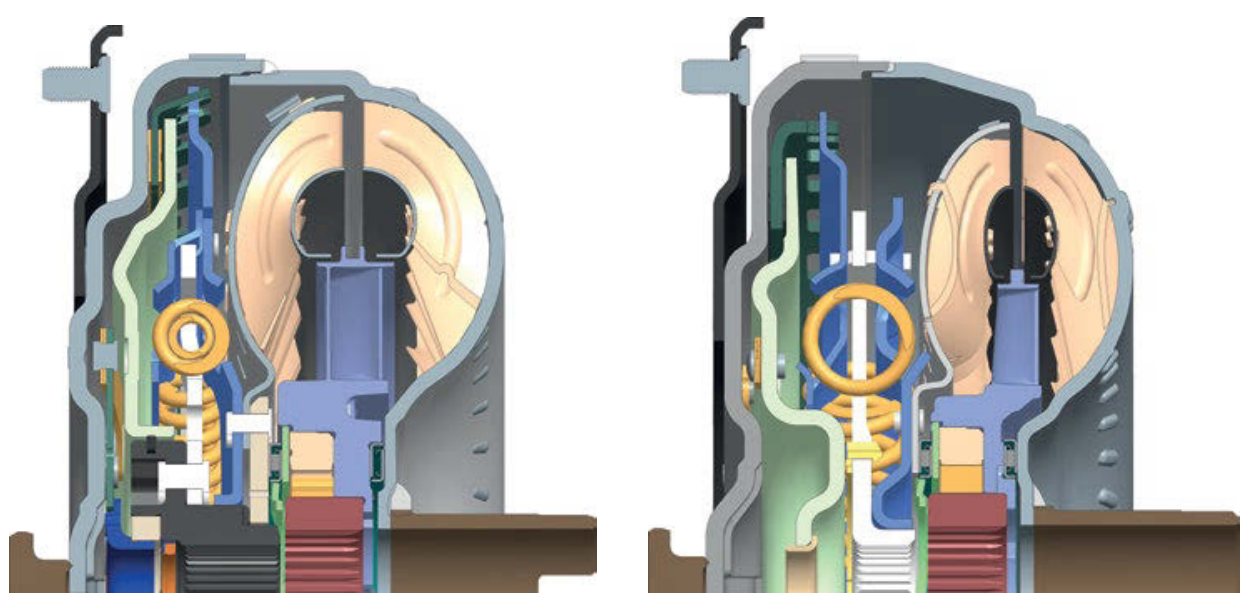

Figure 6 Torque converter designs from 2005 (left) and 2013 (right)

the available space and are therefore directly opposed to requirements for increased damper performance. In the example above, the axial distance between the stud plane and the torus was reduced by $2.9 \mathrm{~mm}$ while the damper windup was increased. These improvements were mainly achieved by reducing the torus width and improving the piston attachment method.

Typical piston attachments for clutches with 2 friction surfaces require a rivet connection outside the piston area. In the 2005 design, this attachment is between the cover and the piston drive plate. For the value enhanced design of 2013 a Schaeffler riveting connection was developed. It establishes a direct leaf spring connection from the cover to the piston without the need for a piston drive plate.

For the Schaeffler riveting process, the leaf springs are attached to the cover assembly. The domed rivets for the leaf

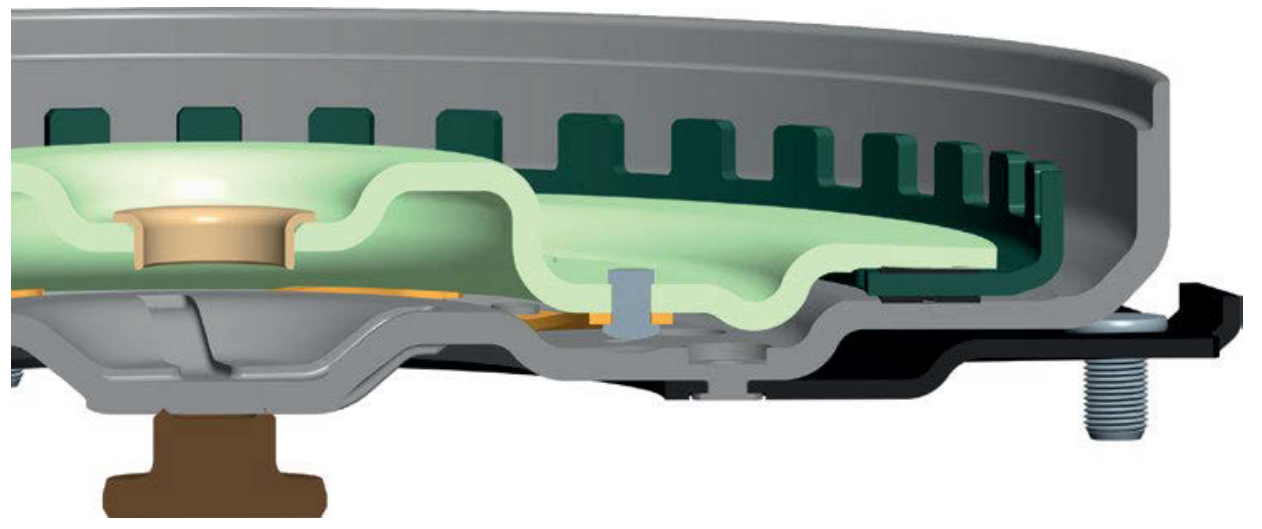

Figure 7 Schaeffler riveting at piston connection 

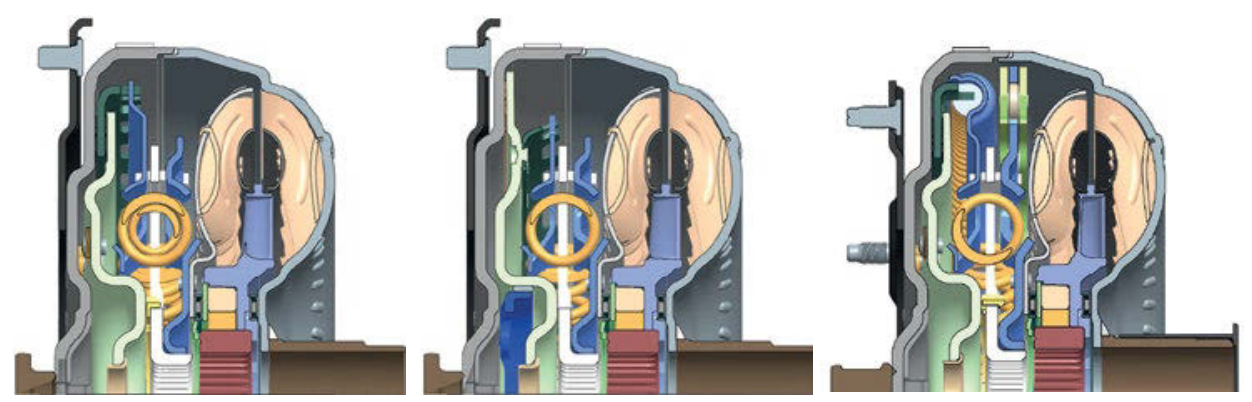

Figure 8 Modularity of the value enhanced torque converter designs from 2013

spring-piston connection are already in place - in a pattern that matches the piston holes. During the piston assembly, the piston is placed on the rivets and the riveting tool pushes it towards the cover until the domed rivet heads make contact with the cover. At this point the rivet head can be formed, establishing a permanent connection between the leaf springs and the piston. The connection was developed so as not to overstrain the piston and to avoid contact between the domed rivet head and the cover in the application.

By eliminating the inner drive plate, the piston could move closer towards the cover, creating more space for the damper.

Reduction of the torque converter cost is a perpetual goal. With the value enhanced philosophy, methods for minimizing the cost were modularization and a reduction in the number of components.

In the 2013 design, the number of components were reduced using the Schaeffler Riveting process piston riveting and redesign of the input shaft interface. The 2005 design uses a riveted hub to connect the damper flange with the transmission input shaft. For the 2013 value enhanced design, a flange was developed that integrates the connection to the input shaft. With the spline formed from the flange, the space requirements were also reduced, leaving more space to optimize the remaining components.
Efforts to focus more on modularity in the development resulted in reduced flexibility and consequently in the increased importance of NVH and durability simulations. It had to be ensured that torque converters would meet customer requirements even with the limited possibility of modifications. The resulting designs are shown in Figure 8. They make it possible to choose between different clutch capacity and gain, damper performance and engine/ transmission interfaces while retaining a large number of common components.

Following the goal of improving powertrain efficiency to reduce $\mathrm{CO}_{2}$ emissions, torque converters are designed to support efficient driving conditions as well as increase the efficiency of the torque converter hydrodynamic circuit or torus.

Between the value enhanced design and its predecessor, the peak torus efficiency was unchanged despite the width reduction and the corresponding weight reduction. This was achieved by improvements in blade design and production methods which allowed the blades to better guide the torus flow.

However, a more significant impact on efficiency is achieved with the damper technology. Increased damper space through the elimination of components in the flange and piston connections permits the use of larger springs. Furthermore, ad- 
vanced damper technology such as centrifugal pendulum absorbers is used to improve the damper function beyond the ability of a coil spring damper in the same envelope. This allows efficiency improvements on a system level as the lockup clutch can be fully locked at lower speeds without compromising $\mathrm{NVH}$.

\section{Centrifugal pendulum absorber for torque converters}

The main driver for advanced damper designs is the challenge of meeting $\mathrm{CO}_{2}$ emission requirements that are placed on modern combustion engines while maintaining or even improving $\mathrm{NVH}$ performance. The trend points towards smaller supercharged or turbocharged engines with fewer cylinders. In order to make the low speed range accessible to the driver, the torque at low rotational speed is increased. From simple physics it can be concluded that the reduction of both the number of cylinders and the drivable rotational speeds result in lower excitation frequencies. This leads to a considerable increase in the engine's cyclic irregularity and torsional vibrations (Figure 9) thus driving the development of damper technology.

The possibilities offered by the new generation of engines require suitable automatic transmissions and drivetrains.

Transmissions must be adapted in line with improvements to engines in order to fully utilize the potential for reducing $\mathrm{CO}_{2}$ emissions. The shift and lockup speeds are reduced to a level that was previously impossible because the available torque was not sufficient in older engines. The aim is to drive at 1,000 rpm and below, not only in the fuel consumption cycle at part load, but also at full load, while reducing the lockup clutch slip as much as possible.

\section{Torsional vibration damper with centrifugal pendulum absorber}

Even with increased installation space for conventional torsional dampers, the isolation of vibrations is often insufficient for modern downsized turbocharged engines. To achieve further improvements in torsional isolation, a speed adaptive ab-
Fuel Consumption Map

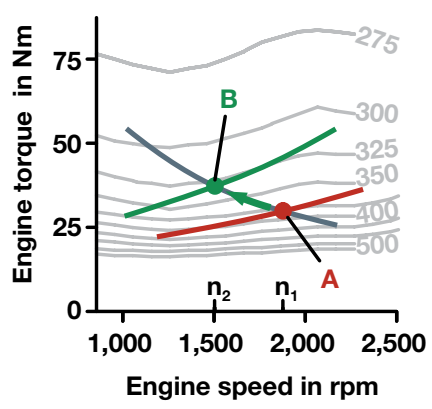

Fuel Consumption

$-14 \%$

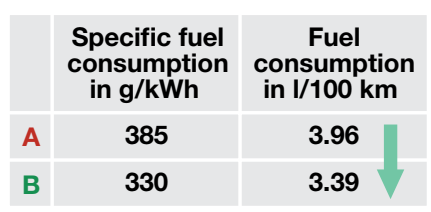

- Drive resistance in $5^{\text {th }}$ gear

- Constant power of $6 \mathrm{~kW}(@ 70 \mathrm{~km} / \mathrm{h})$

- Drive resistance in $5^{\text {th }}$ gear with reduced gear ratio (-20 \%)
Torsional Fluctuations
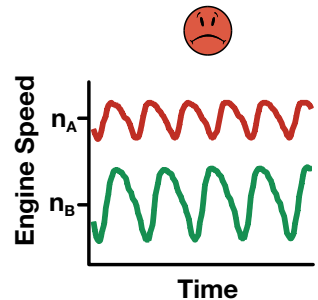

Figure 9 Development trend for downspeeding: drive at low speed for low fuel consumption 
sorber is added to the secondary side of a torsional damper. A speed adaptive absorber changes its absorbing frequency directly proportional to engine speed. The centrifugal pendulum absorber (CPA) incorporates this function and thus can absorb the engine's main firing order optimally.

In practice, a bifilar CPA with two suspension points is used to guide the pendulum mass. It follows a path that can be described as having the pendulum mass suspended by hinged parallel connectors. Each point of the CPA follows the same trajectory and it can be approximated sufficiently as a mathematical pendulum. The CPA movement is guided by rollers which roll on tracks defined by kidney shaped

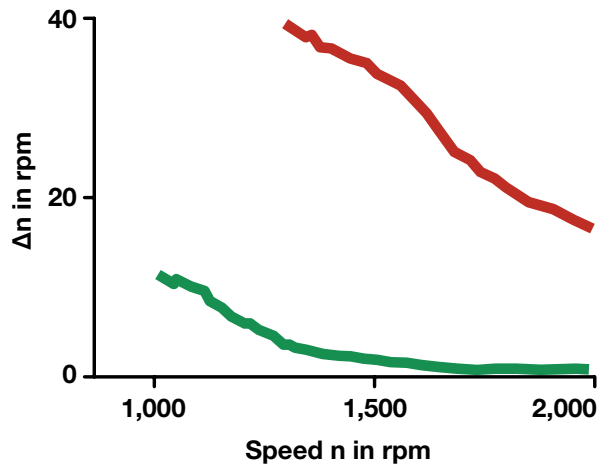

- Standard TD

- DTD with CPA

Figure 11 Comparison of a standard torsion damper with a CPA damper

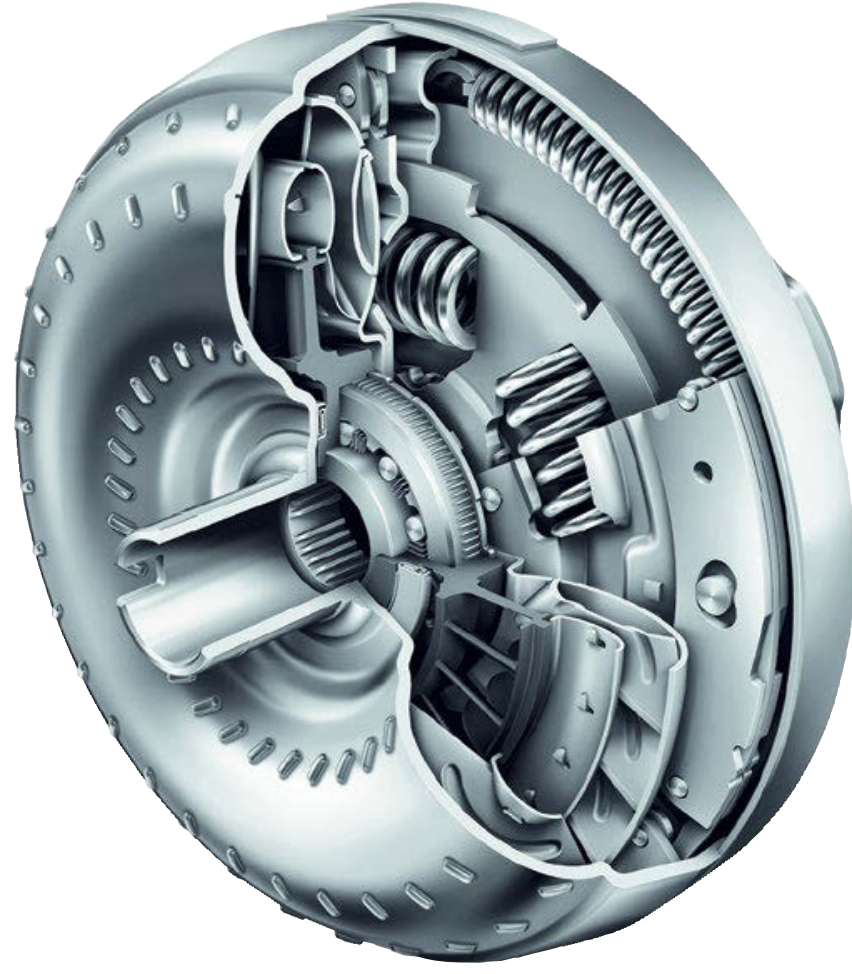

Figure 10 Torque converter with CPA cutouts in the mass and flange. The absorber order is determined by the form of the raceways and the rollers.

The CPA combined with a suitable torsional vibration damper constitutes a significant improvement in the torsion damper's isolation efficiency over standard torsion dampers. Its superiority over other damper concepts has been proven with a centrifugal pendulum absorber attached to a double damper. This design has been in production since 2011. The 


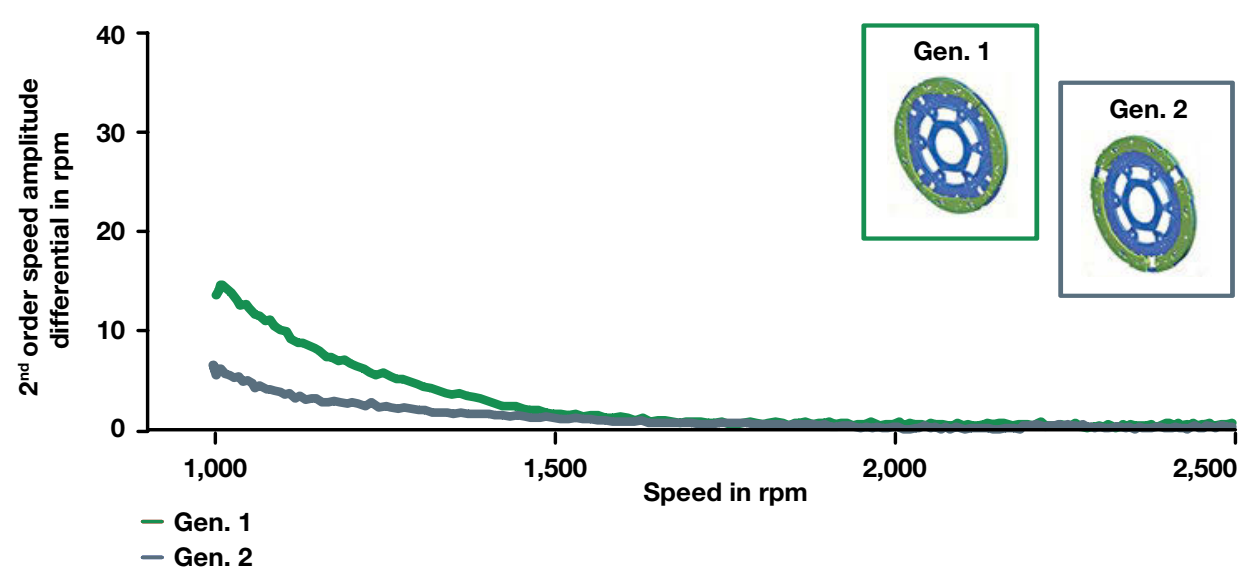

Figure 12 Measurement of vibration amplitude at differential of a $1^{\text {st }}$ and $2^{\text {nd }}$ generation CPA

comparison of this damper design with a standard turbine damper shows a significant improvement in isolation as shown in Figure 11. With this damper it was possible to reach lockup speeds around 1,000 rpm.

\section{$2^{\text {nd }}$ generation centrifugal pendulum absorber for torque converters}

A further increase in the angular displacement and the weight of the parallel CPA would be necessary to improve the isolation capability further and achieve additional fuel efficiency improvements by lowering the lockup speed. Torque converter space and mass limitations however set limits to the CPA growth. The $2^{\text {nd }}$ generation CPA aims to improve of the pendulum efficiency without increasing installation space. It uses optimized movement of the pendulum mass by superimposing a rotation onto the swinging motion of the pendulum mass, similar to a trapezoid (Figure 12). In addition, the $2^{\text {nd }}$ generation allows larger pendulum travel angles to improve the isolation performance. This maximizes efficiency in the given radial space, thus reducing the required pendulum width. Figure 12 illustrates the isolation improvements at low rotational speeds.

Vehicle measurements with the same installation space and damper configuration show a significant reduction in torsional vibrations of approximately $50 \%$ from the $1^{\text {st }}$ to $2^{\text {nd }}$ generation CPA.

\section{$3^{\text {rd }}$ generation centrifugal pendulum absorber for torque converters: \\ track-optimized and spring-loaded}

With ongoing engine and drivetrain optimizations, dampers will have to provide even better isolation of torsional vibrations. Vibration amplitude targets are likely to be reduced while the engine's torsional vibrations increase and the lockup clutch is engaged at lower engine speeds. Furthermore, in the development of automatic transmission drivetrains the focus is on a 


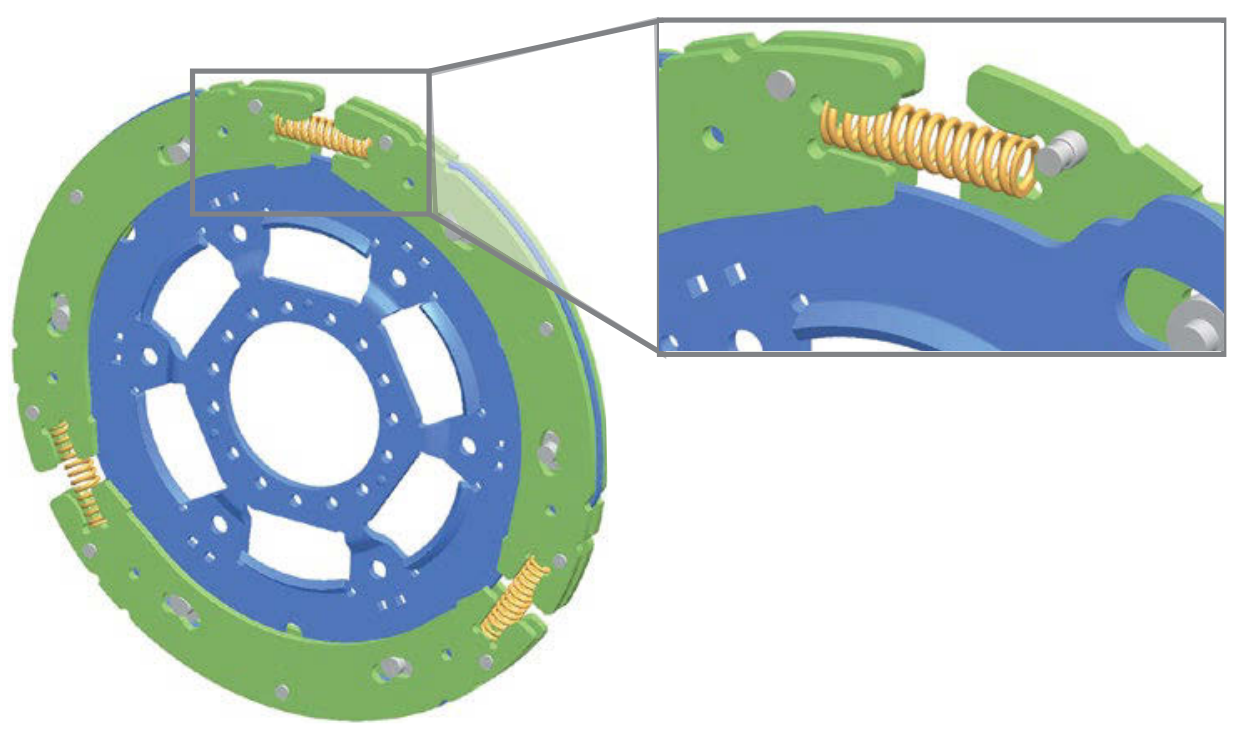

Figure 13 Design of a spring-loaded CPA

higher ratio spread as well as the reduction of transmission damping and drag to improve the efficiency. In combination with the lightweight design of gearboxes and drivetrains, the reduced internal damping leads to structures that are more vibration sensi- tive. Further improvements in isolation will be necessary for these future transmission designs.

With its superior isolation performance the $2^{\text {nd }}$ generation CPA provides an optimal base for additional improvements. Further

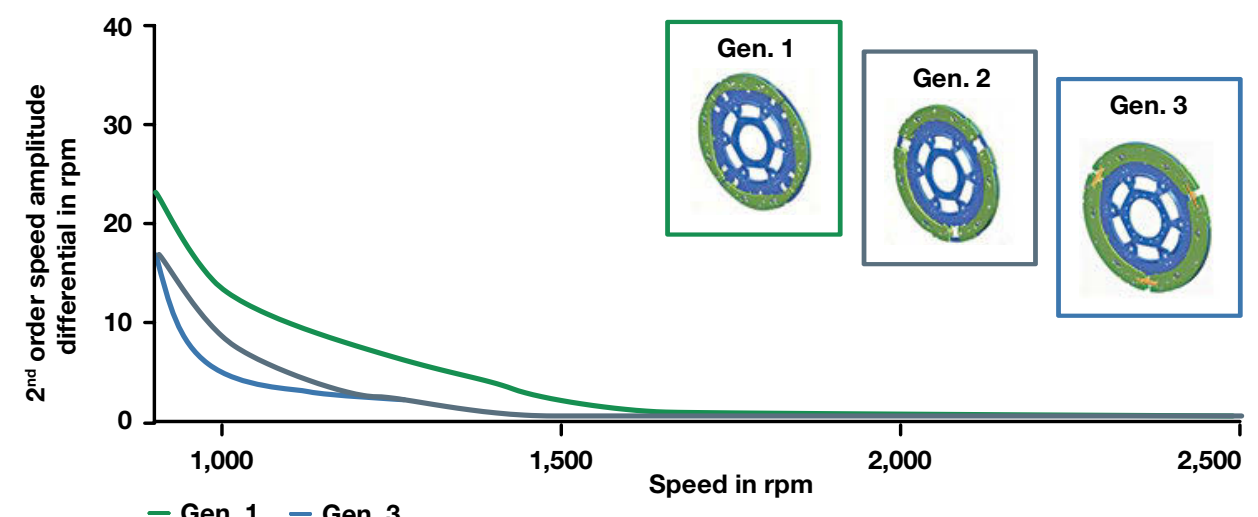

- Gen. 1 - Gen. 3

- Gen. 2

Figure 14 Simulation of isolation with $1^{\text {st }}, 2^{\text {nd }}$ and $3^{\text {rd }}$ generation CPA 
travel-dependent track optimization can improve the pendulum efficiency. The improvements can be focused on situations where significant pendulum travel occurs at low engine speed.

The optimized movement of this pendulum masses enables the addition of a coil spring in between.

The spring force stabilizes the pendulum motion during rotation at creep speed or transition events such as acceleration from standstill, further improving the $\mathrm{NVH}$ of the drivetrain. These additional springs also have a speed-dependent effect on the CPA order which can be minimized by travel-dependent optimization of pendulum tracks.

Figure 14 compares the vibration amplitude at the differential in a drivetrain with a spring-loaded and track-optimized $3^{\text {rd }}$ generation CPA with that of the $1^{\text {st }}$ and $2^{\text {nd }}$ generation.

\section{CPA and \\ cylinder deactivation}

A trend with immense implications on the damper design is cylinder deactivation. It improves the engine's efficiency under partial load by requiring a higher specific load from the active cylinders [11]. The advantage over downsizing and downspeeding is that the high torque of the additional cylinders is still available when needed.

First applications of a CPA with engines capable of cylinder deactivation from 8 to 4 cylinders are already available in the market. Due to the reduction in main firing order while maintaining a high vibration amplitude, isolation in 4-cylinder mode is more challenging than in 8-cylinder mode. Therefore the CPA is tuned to attenuate the 4-cylinder vibrations while the double damper is designed to isolate vibrations in 8-cylinder mode. Besides an increase in sec- ondary inertia, the CPA does not affect the damper performance when the engine runs on all 8 cylinders.

Engines with deactivation from 6 to 3 or 4 to 2 cylinders may require the superior CPA isolation even if all cylinders are used. In this case, two centrifugal pendulum absorbers can be installed with one tuned to each order. This achieves perfect isolation in all driving conditions.

Torsional vibration dampers with $2^{\text {nd }}$ generation CPA are a key technology which allows the lockup clutch to close when the engine speed is to idle. Continuous improvements to the CPA, as described above, provide additional isolation improvement.

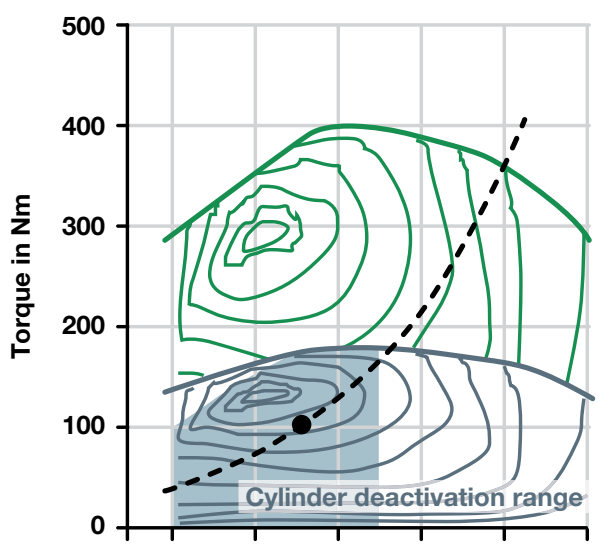

Engine speed in rpm

- Operating point

- 8-cylinder WOT

- 4-cylinder WOT

-- Driving resistance

V8 engine

\begin{tabular}{|l|l|}
\hline 0000 & Active in cylinder deactivation \\
\hline 0000 & Inactive in cylinder deactivation
\end{tabular}

Figure 15 Effect of cylinder deactivation shown in a engine characteristic map [11] 

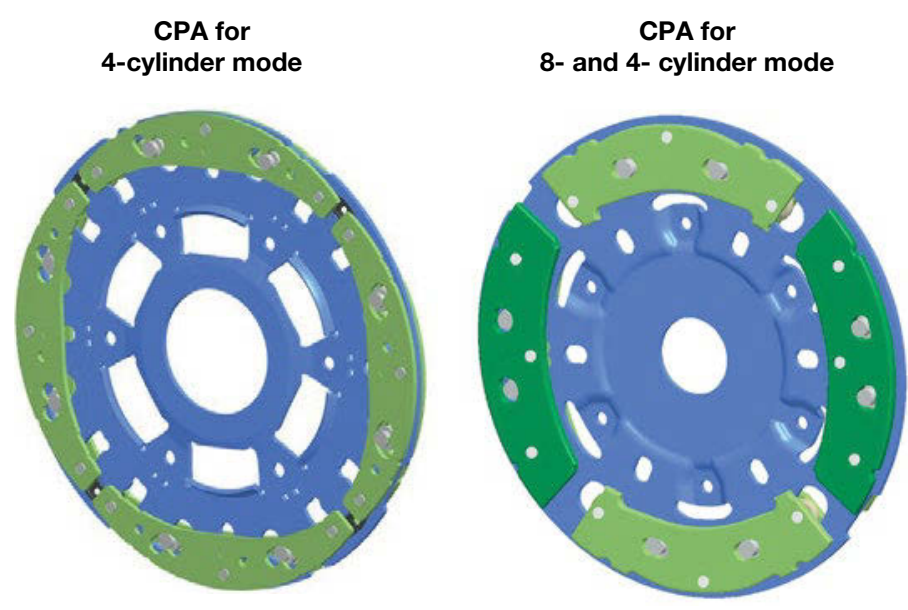

4-cylinder CPA masses

8-cylinder CPA masses

Figure 16 CPA configurations for an application with cylinder deactivation from 8 to 4 .

\section{Torque converter innovation}

As discussed in the previous chapter, installation space for the torque converter is becoming increasingly and smaller. Nevertheless the requirements for torsional isolation are becoming increasingly demanding. One approach to improve the damper performance is to increase the damper space by reducing the torus width and creating a squashed torus design.

This conventional approach has been used before and its potential to increase the damper space is limited. To find even more damper space it was necessary to overcome the usual restrictions of torque converter design by incorporating the piston function into the turbine. In a traditional design the turbine and lockup clutch are separate components. Both functions will be required in torque converters for the foreseeable future. By increasing the functions performed by the turbine, one of the large components of a typical torque converter design the piston - can be eliminated.

This requires the turbine design to change to withstand the actuating pressure. However, in traditional torque converters, the piston takes up more space than its thickness. It requires clearance to the cover, clearance for piston deflection and more clearance to the damper to avoid contact during operation. The turbine thickness must to be increased with this design in order to withstand the lockup clutch actuating pressure. Ultimately, the

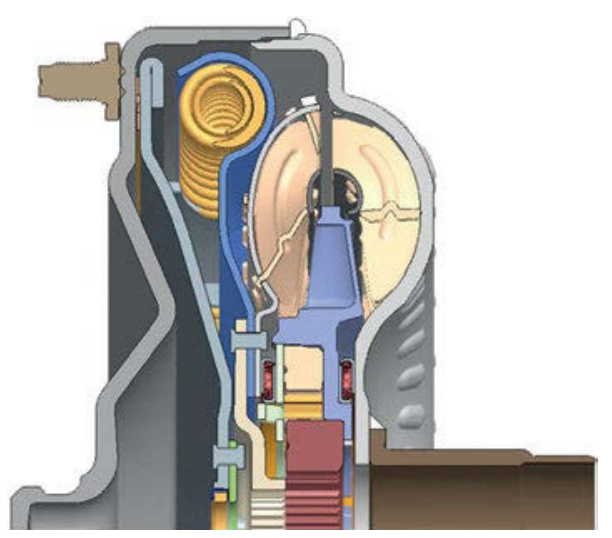

Figure 17 Typical FWD torque converter design 


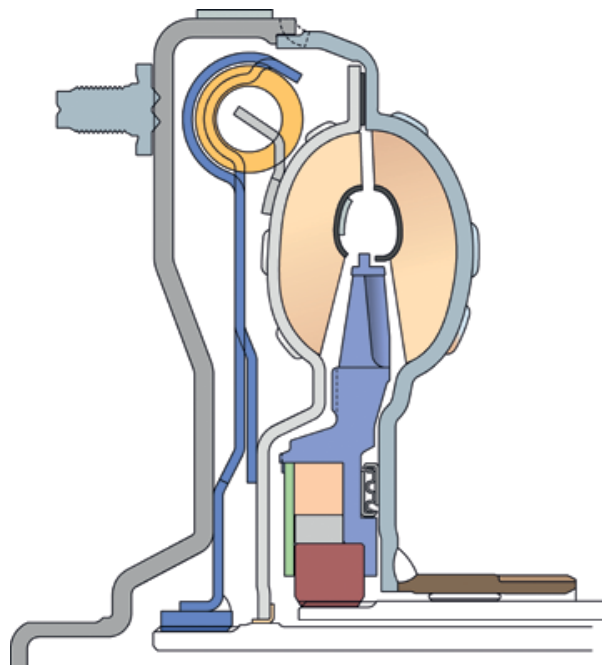

Figure 18 Initial iTC design

space gained from the elimination of the piston as a separate component outweighs the thickness increase of the turbine.

Turbine and impeller now fulfill the lockup function. During a vehicle launch the turbine is active, providing the required torque multiplication. At higher vehicle speeds, the lockup clutch can engage and create a torque path to bypass the hydrodynamic circuit.

By integrating the piston into the turbine, the actuation direction is opposite to the typical torque converter design. Instead of actuating in the direction of the engine, the lockup clutch now actuates in the direction of the transmission. This means the lockup clutch apply and release channels have to be controlled in reverse to a typical torque converter.

The lockup clutch engagement control distinguishes between 2 stages: open condition and lockup or slip condition. In the open condition, oil enters the torque converter through the torus, building a higher pressure on the turbine's transmission side and thus causing the clutch to lift off. To avoid cavitation at low speed ratios, the torque converter charge pressure is elevated even with the lockup clutch disengaged. This leads to a cooling flow of 5 to $10 \mathrm{l} / \mathrm{min}$. This is more than sufficient to balance the turbine thrust and ensure that there is an oil layer between the ITC friction surfaces. Measurements have shown that this design lowers the clutch drag in torque converter mode to almost zero.

To engage the lockup clutch, oil is directed through the center of the input shaft and generates a pressure difference on the turbine. A bushing on the inside diameter of the turbine seals the turbine off from the input shaft and ensures that flow has to pass through the friction surface and build actuation pressure for the lockup clutch to engage towards the impeller. The lockup clutch engagement requires a more detailed examination of the turbine thrust.

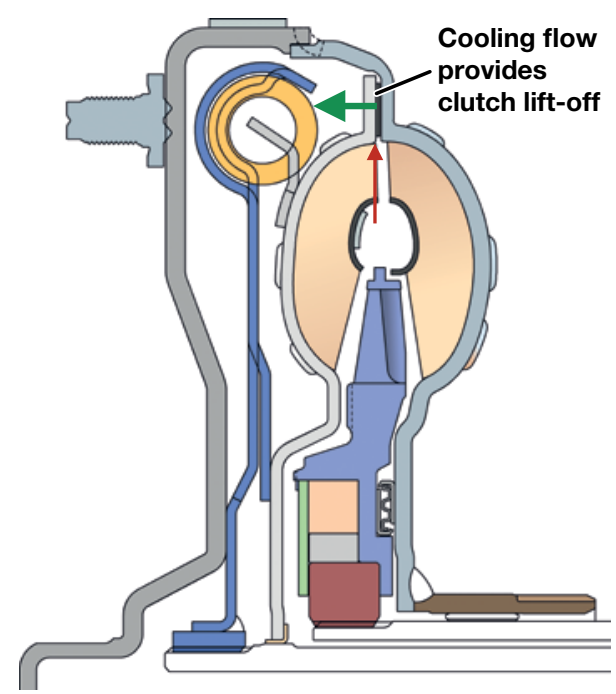

Figure 19 ATF flow in lockup clutch disengagement 

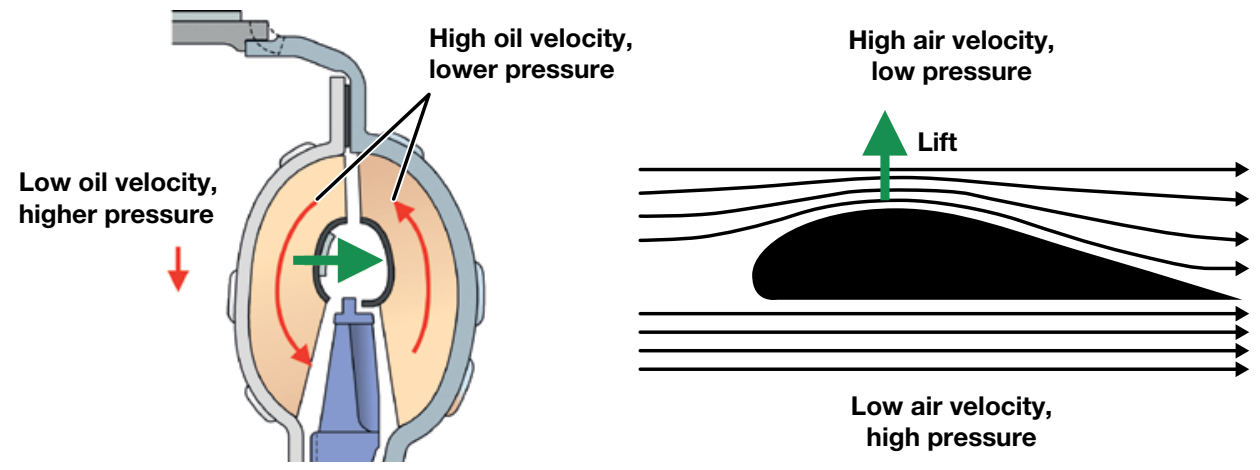

Figure 20 Cause of turbine thrust

\section{iTC Measurements}

Turbine thrust is a result of different oil velocities on both sides of the turbine. Inside the torus, the oil circles between the impeller and the turbine with a velocity that depends on the speed difference between both components. The velocity is at its highest when the vehicle is at a standstill ("stall").On the engine side of the turbine, the oil velocity is considerably lower. Only shear stress on the cover and impeller cause the oil to have a different speed to the turbine. Using Bernoulli's Principle, the axial force on the turbine is easily explained. High oil velocity causes the oil pressure to drop which creates a pressure difference between both sides of the turbine and results in a force towards the higher velocity oil. It is the same physical principle that allows airplane wings to create lift.

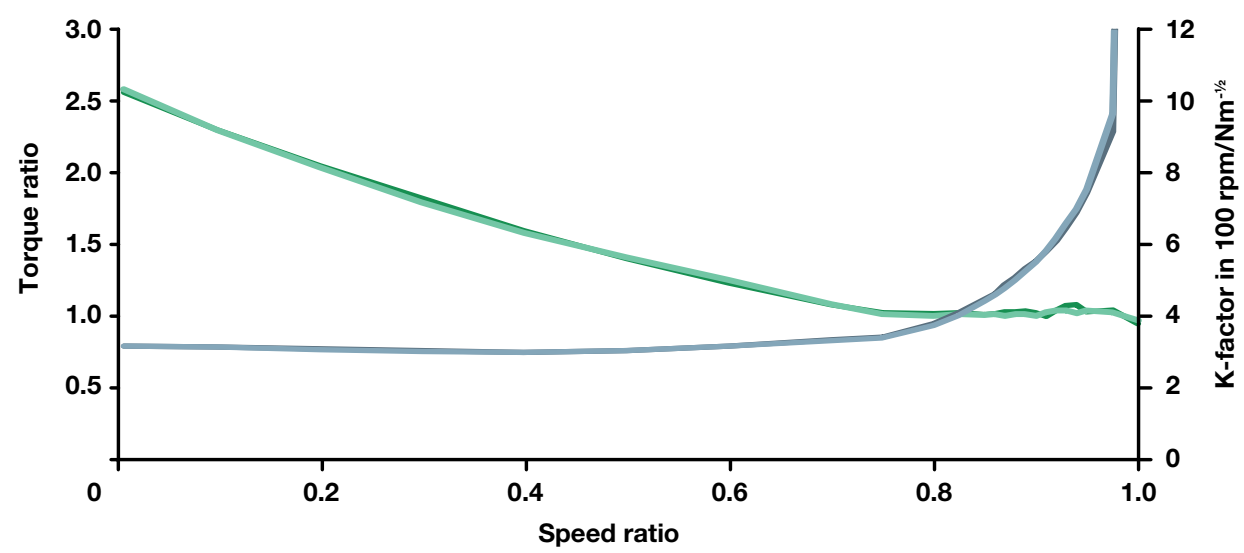

\footnotetext{
- Torque ratio, blocked iTC - K-factor, blocked iTC

- Torque ratio, iTC $\quad-$ K-factor, iTC
}

Figure 21 Characteristic measurements of iTC and blocked iTC 


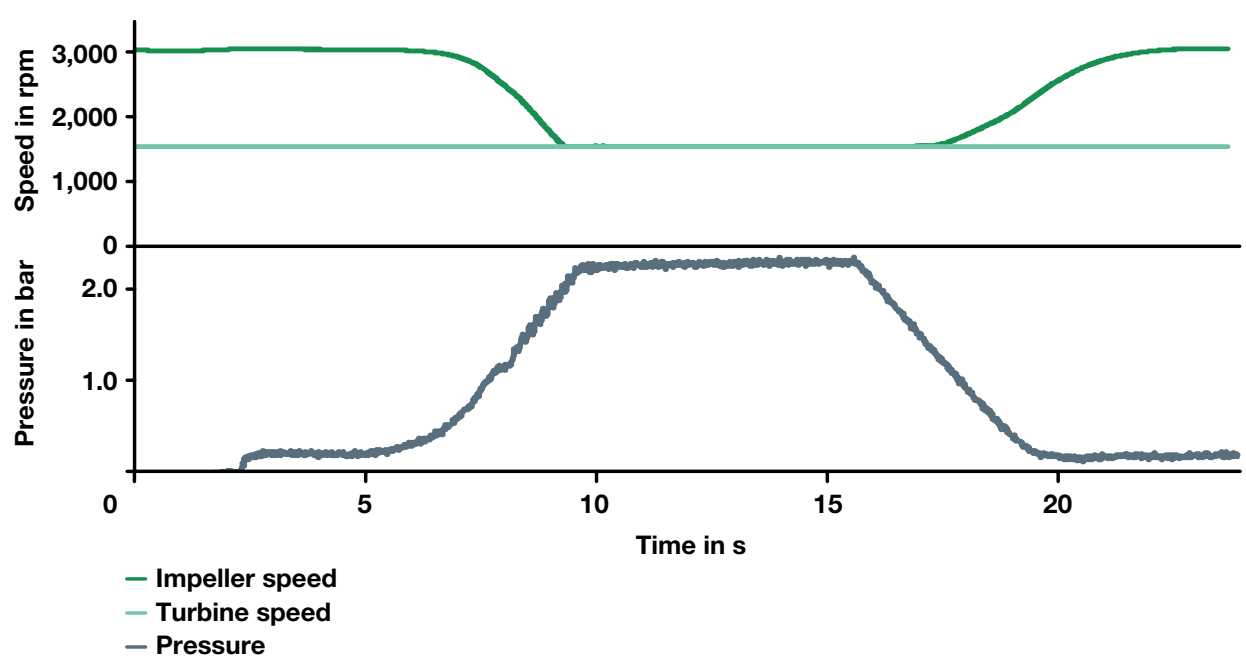

Figure 22 Torque converter characteristic and lockup clutch engagement measurements

At first glance the turbine thrust might seem to be an obstacle. Closer examination however shows that the turbine thrust can be balanced with TC charge pressure to disengage the lockup clutch. This creates a hydrostatic support at the turbine's friction surface and leads to low clutch drag. Engaging the lockup clutch creates a force that is oriented towards the transmission - the same direction as the turbine thrust. For the lockup clutch engagement, turbine thrust means that the gap between the lockup clutch friction surfaces has a tendency to be reduced every time there is relative speed between the turbine and the impeller. This is a preliminary stage to the closure of the the lockup clutch and allows a smooth engagement.

Measurements of the iTC confirm the theoretical considerations about clutch drag and engagement. An iTC prototype was prepared for the comparison of TC characteristics between an iTC design and a typical torque converter. The first characteristics measurement was taken on the ITC prototype, for the second mea- surement a rolling bearing was placed between the turbine and the stator to increase the clutch lift-off and prevent it from engaging. The measured characteristic curves are nearly identical and only differ in terms of measurement accuracy. This shows that the turbine bearing exhibits the same resistance the friction surface lifted off by the oil flow, as previously described.

The clutch controllability and engagement quality was checked in a dynamometer test where the turbine and impeller spin is at a given speed and the actuation pressure is increased gradually. After a successful engagement, the actuation pressure is reduced to determine when the clutch starts slipping again.

As expected, the engagement starts at low actuation pressure values and does not lead to a torque spike. The pressure value at which the slip ended during the engagement phase and the pressure value at which the slip started during the disengagement phase are also identified as very close. This small engagement hysteresis verified the ITC slip controllability. 


\section{iTC Advantages}

As described above, the main motivator for the ITC design is in the reduction of the torque converter width. This goal coincides with the trend towards drivetrain weight reduction and increasing numbers of gears. Besides the space advantage, the iTC provides the following improvements over a typical torque converter.

The iTC has less components when compared to a typical torque converter. All of the turbine's axial force is directed through the friction surface and the turbine never makes contact with the stator, therefore it does not require a turbine bearing. The ITC also reduces the number of components by avoiding multiple connections for the damper torque input and by removing the piston. This reduces the design complexity but its major effect is a cost and weight reduction. The turbine has to be thickened to withstand the lockup pressure but this is more than outweighed by removing the components mentioned above.

On the functional side, the ITC provides very smooth engagements through an effect that is comparable to a preloaded clutch but without the clutch drag caused by a preload mechanism. The self-engagement of the iTC is stronger at higher relative speeds between turbine and impeller because the turbine thrust force depends on the speed ratio. This results in an increased engagement stability and reduces the risk of clutch shudder. As a result of the lockup clutch proximity to the torus, the clutch interface is stiffer than in a typical torque converter. The
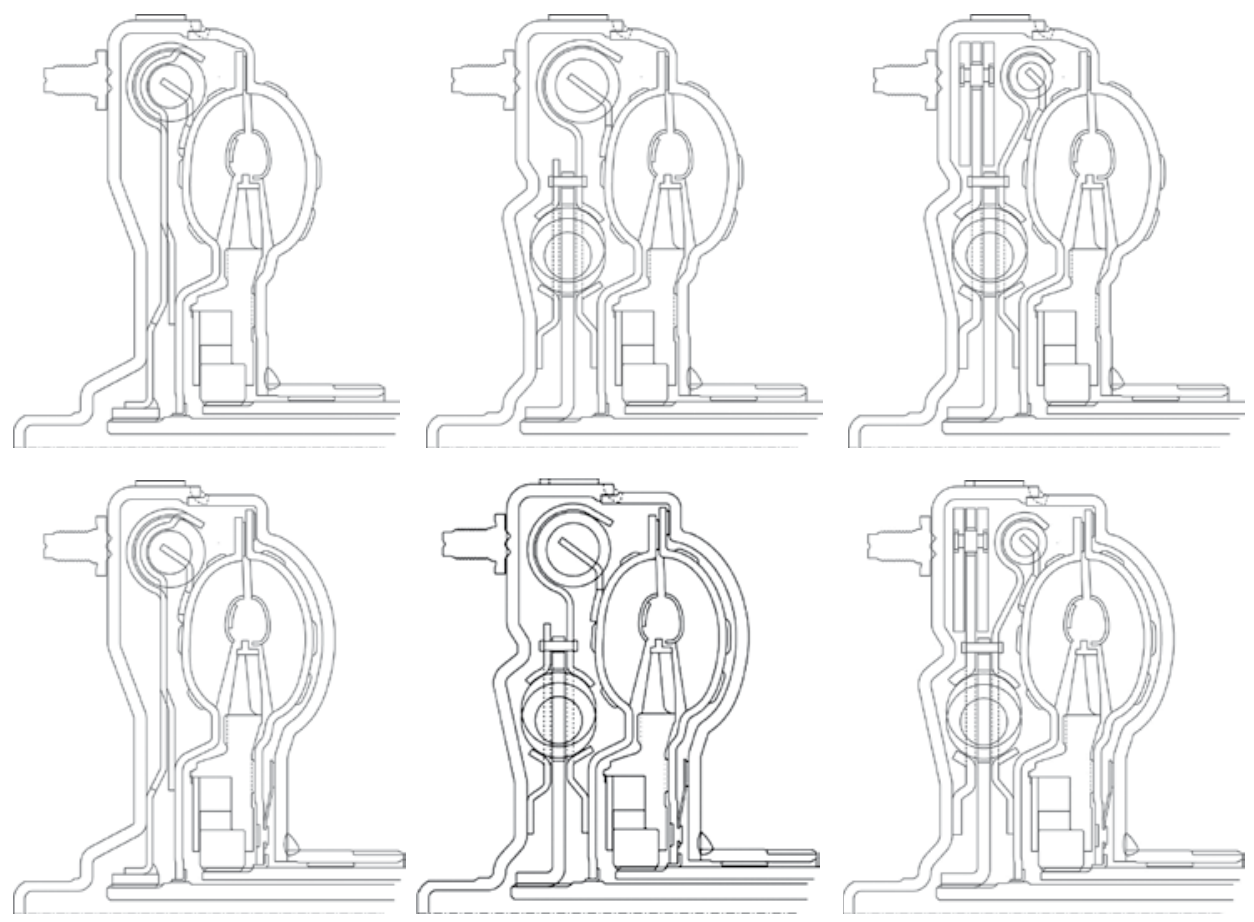

Figure 23 Modular damper and torus designs with the iTC layout 
brazed blades add a rib-like effect to the turbine and impeller shell and reduce the friction surface taper that would otherwise result from the apply and ballooning pressure. With less taper, the power input on the friction surface has a more equal distribution which avoids localized high temperatures and wear.

\section{iTC modularity}

Modularity was already the goal for the value enhanced design described above. With the iTC however, modularity receives an enabler that hasn't been available before. Typical torque converters require the damper to have connections to both the piston and the turbine. The iTC design has only a single input to the damper. This reduces the damper complexity which creates space for higher performing dampers and reduces the obstacles to variations of the damper.

The iTC modularity doesn't only extend to damper variations as shown in Figure 25. Due to the relative simplicity of the impeller clutch design, its addition becomes modular and the result is more predictable.

\section{One way clutch}

Since 1928, one way clutches have been used to switch from converter to coupling mode. Typically, roller or sprag designs are used in torque converters. Driven by the width reduction that is achieved with the iTC design, the focus falls on reducing also the one way clutch width.

Two concepts are available to reduce the one way clutch width. On a sprag or roller one way clutch, the contact surfaces are coaxial, therefore the capacity cannot be increased without increasing the width. In the wedge design, the contact surfaces are arranged circumferentially. The wedge one way clutch locks if the outer race pulls the wedge plate onto the inner race ramps. Utilizing the wedge principle, the normal force on the wedge plate increases with torque and creates a self-energizing friction coupling. In the freewheel direction, the wedge plate is prevented from spinning by the inner race shoulders. The wedge plate design is adjusted to only create drag in lockup direction to slide up the ramps. In the freewheel direction, the plates are designed to reduce the drag. Due to the arrangement of the contact surfaces, this design has a considerable width reduction over typical roller one way clutches.
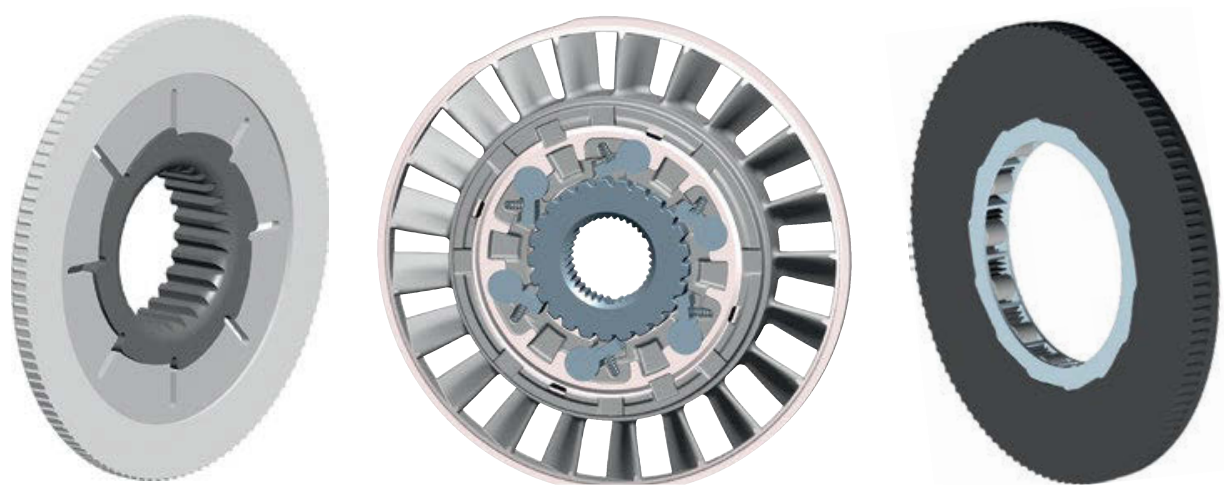

Figure 24 Wedge (left), rocker (center) and slim cage one way clutch (right) 
A second design with reduced width aims to eliminate non-functional features. Pedestals on the outer race of a typical roller one way clutch provide a reaction surface for the preload springs but their width is mainly driven by the production process. By using a plastic cage, the number of rollers can be permitting a reduction in their length.

Yet another one way clutch development is the rocker design. This design aims to reduce the cost of the torque converter. Since the rocker location is fixed with respect to the stator, the outer race can be removed and the contact surfaces can be integrated into the stator's aluminum body. The contact surface can be increased to avoid plastic deformation by the rockers. This design creates a challenge since it can only engage at discrete positions. It has been shown however, that a lash angle of $2.4^{\circ}$ is small enough to avoid any noticeable difference between the rocker and a roller one way clutch. With the elimination of a part as complex as the outer race of a roller one way clutch, this design reduces the cost of the torque converter.

\section{Multi Function iTC}

Unlike the typical lockup clutch, the iTC design allows the implementation of an impeller clutch without large design changes. As the addition of a shell to the outside of the impeller cannot be avoided, the axial dimensions are increased. However, the impeller clutch can be integrated into the iTC's turbine clutch and the pressure channels can also be adapted with ease.

The reason for an impeller clutch traces back to the increase in the combustion engine's efficiency. With a trend toward turbocharged engines with a smaller number of cylinders, the maximum engine power is not available below 3,000 rpm. A highly boosted engine can struggle to reach full torque in a timely manner under heavy load at low speeds, commonly called turbo lag. This can cause poor vehicle launch performance and feel. To mitigate this effect and allow the engine to reach high speeds during a launch, the torque converter would typically be designed with a high K-factor to make it softer. The high K-factor has another advantage in that it results in reduced idle losses. As a detriment, high K-factor allows the engine to flare to higher speeds when the lockup clutch disengages for torque multiplication. In this case, a lower K-factor would be desired to make the torque converter stiffer.

Both can be achieved if the impeller is not hard connected to the engine. The impeller clutch allows the engine to have a higher speed than the impeller which allows the engine to provide a higher torque faster, diminishing turbo lag. This function can then best be described as a variable K-factor. The Multi Function ITC is designed to the lowest desired K-factor and the impeller clutch slip is used to make the system softer.

The MFiTC controls require the 2 standard pressure channels and an additional channel from the back of the impeller

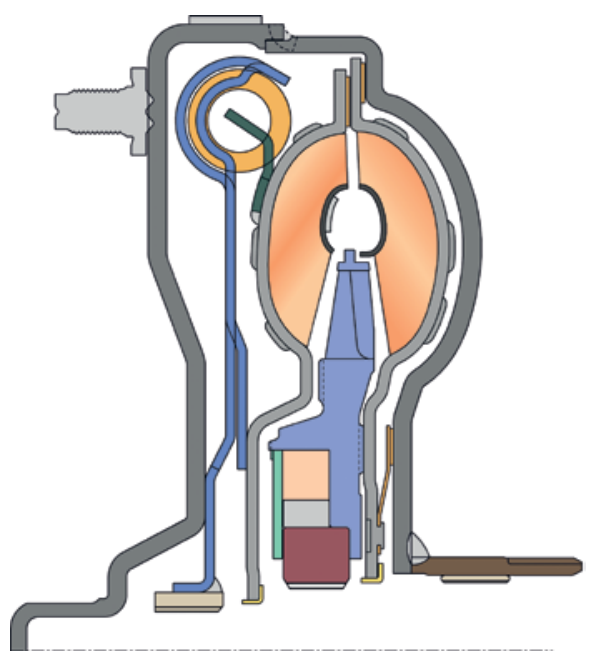

Figure 25 Multi Function ITC 
clutch into the sump. Pressure between the turbine and impeller press the impeller against the transmission side cover and connect it to the engine. The channel through the center of the input shaft has to be closed to force the oil flow to exit through the impeller hub. The slip that is required to modify the torque converter stiffness can be controlled through the oil flow that enters between the turbine and the impeller. For the engine start and in idle, the channel through the transmission input shaft is opened which eliminates the pressure difference on the impeller and opens the clutch. The engine can therefore start without the drag that is typical of nonmulti function torque converters.

Lockup is achieved by providing oil flow through the input shaft to the outside of the turbine shell. This presses not only the turbine but also the impeller towards the outer shell and engages both clutches. Transitions between the lockup and torque converter modes require controlled backpressure on the exit channel to prevent the engaged clutch from slipping.

\section{Summary}

The torque converter as it is used in modern transmissions is the result of an evolution that spanned more than 70 years. Improvements of the internal combustion engine and the automatic transmission caused the torque converter design to be adapted but torque converter development itself has left a mark on the automatic transmission market as well. Smooth launch, torque multiplication and the attenuation of torsional vibrations set new directions for both engines and transmissions. The iTC is a continuation of this evolution and the space that was freed by integrating the piston into the tur- bine increases the degrees of freedom in the powertrain design.

Similarly, torsional vibration dampers with $2^{\text {nd }}$ generation CPA will be a key technology. It allows the powertrain to be used close to idle speed with the lockup clutch engaged for fuel efficiency. The CPA is independent of the torque converter design. It can be paired with a regular TC as well as an iTC to meet future demands of downsizing and downspeeding.

\section{Literature}

[1] IHS Automotive Production Forecast, Aug 2013

[2] Naunheimer, Bertsche, Lechner: Fahrzeuggetriebe. Berlin: Springer, 2007

[3] Thompson E. A.: Fluid Coupling Rotor, US Patent 2,357,295. 1940

[4] Rieseler H.: Flüssigkeitswechsel- und -wendegetriebe, German Patent 435662, 1921

[5] Föttinger H.: Improvements, GB Patent 190906861, 1009

[6] Föttinger $\mathrm{H}$.: Flüssigkeitsgetriebe mit einem oder mehreren treibenden und einem oder mehreren getriebenen Turbinenrädern zur Arbeitsübertragung zwischen benachbarten Wellen, German Patent 221422, 1905

[7] Föttinger $\mathrm{H}$.: Flüssigkeitsgetriebe zur Arbeitsübertragung zwischen benachbarten Wellen mittels treibender und getriebener Räder, German Patent 238804, 1905

[8] Janssen P., Govindswamy K.: Future Automatic Transmission Requirements, FEW, 2013

[9] Autocar Handbook, 13th edition, 1935

[10] Krause, T.; Kooy, A.; Kremer, E.: Torsional Dampers with $2^{\text {nd }}$ Generation Centrifugal Pendulum Absorber for Manual and Automatic Transmissions; VDI Congress Getriebe in Fahrzeugen, 2011

[11] Golloch, R.: Downsizing bei Verbrennungsmotoren, Springer, 2005

Open Access. This chapter is distributed under the terms of the Creative Commons Attribution Noncommercial License, which permits any noncommercial use, distribution, and reproduction in any medium, provided the original author(s) and source are credited. 